\title{
Breast Cytology: Current Issues and Future Directions
}

\author{
Malini Harigopal ${ }^{*}$ and David C. Chhieng
}

Department of Pathology, Yale University, 430 Congress Avenue, New Haven, CT, USA

\begin{abstract}
Breast cytology, in particularly fine needle aspiration biopsy (FNAB), has been used for many years as a diagnostic tool for managing patients with breast lesions. In experienced hands, FNAB is highly sensitive and specific. Other benefits include its low cost, minimal invasiveness, and ability to provide same-day diagnosis. Despite all these benefits, FNAB has gradually been replaced by core needle biopsy (CNB) because of its high error rates when there is a lack of experienced cytopathologists, its inability to distinguish between invasive and in situ carcinoma, and most importantly, its inability to provide adequate and suitable materials for quantitative evaluation of HER2 and other prognostic markers. Other uses of breast cytology include touch preparation cytology for intraoperative evaluation of sentinel lymph nodes and surgical margins of lumpectomy specimens and for providing same-day diagnosis of CNB. In addition, breast cytology, such as ductal lavage and nipple fluid cytology, has also found applications in risk assessment for women at high risk for developing breast cancer. With the increased utilization of molecular technologies, genomic and proteomic studies have been successfully applied to breast cytologic preparations. It would not be far fetched to predict that in the very near future, the clinical application of molecular analyses will be routine ancillary testing in breast cytology, thus allowing early cancer detection, and improved tumor characterization as well as prediction of patients' outcomes and therapeutic responses.
\end{abstract}

Keywords: Breast cytology, FNAB, CNB, breast cancer.

\section{INTRODUCTION}

Breast cytology, particularly fine needle aspiration biopsy (FNAB), has been an integral part in the management of women with breast lesions. Although its use has gradually reduced in the United States, Canada, and the United Kingdom, FNAB continues to be used worldwide, especially in developing countries, for the initial management of breast lesions [1-10]. In addition, breast cytology has been established as a viable alternative for intraoperative examination of breast specimens. More recently, breast cytology, such as ductal lavage, has been utilized as an individual risk assessment tool for women at high risk for developing breast cancer. In this review article, the benefits and limitations of FNAB in the diagnosis of breast lesions are examined. We shall also discuss the use of breast cytology in intraoperative examination of breast specimens and as a risk assessment tool. Last but not least, the applications of molecular testing to breast cytology will also be explored.

\section{FINE NEEDLE ASPIRATION BIOPSY}

FNAB was first introduced in 1930 [11]. Over the years, it has been widely accepted as a first line diagnostic procedure for patients with breast lesions. However, since the beginning of the new millennium, there is a gradual decline in the popularity of FNAB and an increased usage of core needle biopsy (CNB) in the preoperative assessment of breast cancer in the United States, Canada, and the United Kingdom [1-3] The reasons for the loss of popularity for

*Address correspondence to this author at the Department of Pathology, Yale University, 430 Congress Avenue, New Haven, CT, USA; Tel: (203)

785-3853; Fax: (203) 785-2641; E-mail: malini.harigopal@yale.edu
FNAB include high error rates due to a lack of experienced cytopathologists at individual laboratories. In addition, the belief that the inability of FNAB to provide adequate and suitable samples for assessment of prognostic markers also contributes to the decline. Nevertheless, FNAB continues to be used worldwide, especially in developing countries, for the management of breast lesions [4-10].

\section{Current Indications of FNAB in the Management of Breast Lesions}

Currently, the indications for FNA of breast lesions include

1. Evaluation of cystic lesions.

2. Diagnosis of recurrent or metastatic breast cancer.

3. Confirmation of locally advanced cancer.

4. Axillary staging of patients with invasive breast cancer.

\section{Diagnostic Accuracy}

One of the arguments for the replacement of FNAB by $\mathrm{CNB}$ is the high error rate due to a lack of experienced cytopathologists. However, in experienced hands, FNAB is a highly accurate diagnostic procedure. Recent review demonstrates that breast FNAB has a sensitivity ranging from $76 \%$ to $99 \%$, a specificity from $60 \%$ to $100 \%$, and a diagnostic accuracy from $72 \%$ to $95 \%$ [12]. For palpable breast lesions, both the sensitivity and specificity are over $95 \%$ $[13,14]$. While the specificity for both FNAB and CNB approaches $100 \%$; FNAB may be more sensitive (97\%) vs $90 \%$ for CNB in the diagnosis of palpable breast cancers [15].

For nonpalpable breast lesions, FNAB under image guidance is also comparable to image-guided $\mathrm{CNB}$. In one study, 1,885 FNAB with ultrasound guidance of nonpalpable 
lesions over a 68-year period was analyzed [16]. Based on combined histologic and clinical follow-up, the authors reported a sensitivity of $97 \%$ and specificity of $99 \%$ for ultrasound guided FNAB when definitive benign and malignant diagnoses were considered. Based on a multicenter study evaluating over 2,400 women who underwent image-guided FNAB followed by image-guided $\mathrm{CNB}$ of nonpalpable breast abnormalities, the sensitivity (89\%) of CNB for diagnosing all lesions was significantly lower than that of FNAB (97\%) [17].

The positive and negative predictive values of breast FNAB range from $94 \%$ to $100 \%$ and from $67 \%$ to $96 \%$, respectively [12]. False positive diagnoses are rare $(0-3 \%)$ and are usually the result of interpretative error [12]. Pregnancy related changes, fibroadenoma, therapeutic changes, fat necrosis, and papillary lesions are some examples that can lead to false positive interpretations [10]. On the other hand, the false negative diagnoses have been reported to be in the range of $3 \%$ to $18 \%$ and can be attributed to either sampling or interpretative errors [12]. Low-grade ductal carcinoma, lobular carcinoma, and mucincous carcinoma, are some examples of lesions that may be associated with underinterpretation $[10,18]$. However, the majority of the false negatives are due to sampling errors. To reduce false negative diagnoses, it is important to apply the triple test for accurate diagnosis in each patient [9]. The triple test is the combination of clinical, radiologic, and cytologic findings in arriving at a diagnosis. If all three components are negative, the negative predictive value approaches $100 \%$ [19]. On the other hand, if any discordance exists among any of the 3 components, further investigations, such as excisional biopsy, should be contemplated.

\section{Distinction Between In Situ and Invasive Carcinoma}

Because of the difference in the management in regard to sentinel node biopsy and the use of pre-operative neoadjuvant chemotherapy, it is imperative to determine if a breast cancer is in situ or invasive. Because of the lack of reliable cytologic features to distinguish between in situ and invasive breast carcinoma on FNAB [20-22], histologic examination is preferred. However, CNB suffers from sampling errors too; up to $20 \%$ of cases diagnosed as in situ carcinoma only on CNB were found to be associated with invasive carcinoma on subsequent surgery [23, 24]. As a matter of fact, over $95 \%$ of FNAB with a malignant diagnosis in the presence of either a palpable mass or a speculated appearance on imaging showed invasion on histologic follow up $[25,26]$.

\section{On Site Assessment}

The advantage of FNAB is that it is fast, inexpensive, and minimally invasive. The results are rapidly available. A preliminary diagnosis can be given by a cytopathologist within 5-10 minutes after the procedure. In most cases, a definitive diagnosis can be given within 24 hours. Because a diagnosis can be made available on the same day as the procedure, this would enable "one-stop shopping" in a multidisciplinary setting, i.e. allowing the clinicians to discuss the diagnosis with the patient, proceed with further investigation, and help with subsequent management and treatment without delay.
Another benefit of on-site assessment is the reduction in the number of unsatisfactory or inadequate samples. Additional passes can be performed immediately when a specimen is designated as inadequate. Nasuti et al. has shown that with on site adequacy assessment, the nondiagnostic rate was less than $1 \%$ whereas the non-diagnostic rate was $20 \%$ when on site evaluation was not performed [27]. Unfortunately, reimbursement for pathologists performing on site assessment was inadequate [28]. Furthermore, not all centers have the expertise to provide such service.

\section{Ancillary Studies and Molecular Testing}

Perhaps the strongest argument against FNAB is its inability to provide adequate and suitable samples for the evaluation of predictive factors, such as estrogen and progesterone receptors (ER and PR) and HER2. As a result, more expensive and invasive procedures, such as $\mathrm{CNB}$, are required for obtaining additional tissue for ancillary testing once a malignant cytologic diagnosis is made. Breast FNAB is, therefore, judged as incurring additional costs and delays in patient management.

One of the challenges in utilizing cytologic samples for evaluating predictive and prognostic biomarkers is meeting the fixation requirement recommended by the recently published American Society of Clinical Oncology/College of American Pathologist (ASCO/CAP) guidelines for quantitative analysis of HER2 expression [29] According to the recommendations, breast specimens should be fixed for a minimum of 6 hours and a maximum of 48 hours duration in $10 \%$ neutral-buffered formalin. Most cytologic samples, including direct smears, liquid-based preparations, and cell block preparations, are often fixed in $95 \%$ ethanol. A recent study shows that there was only a moderate positive agreement of $73 \%$ (weighted Kappa of 0.57 ) between ethanol-fixed and formalin-fixed tissue samples with HER2 immunohistochemistry [30]. The lack of agreement is mainly attributed to the fact that ethanol-fixed cell block preparations more frequently demonstrate overexpression of HER2 immunostaining when compared to formalin fixed tissue samples, resulting in false positive results. On the other hand, excellent correlation for ER and PR results were noted between ethanol-fixed cell block preparations and formalin-fixed tissue samples [30].

Cytology material obtained by FNAB has been shown to provide good quality of DNA and RNA with a yield that is comparable to that of CNB. In a study comparing FNAB to CNB for transcriptional profiling, the authors showed that FNAB samples were more representative of tumor cells and had $80 \%$ tumor cells versus $50 \%$ for CNB and $5 \%$ stromal cells in FNAB versus $30 \%$ in CNB [31]. Recent developments in molecular technologies, such as gene expression profiling, could complement traditional cytology by allowing early cancer detection, and improved tumor characterization as well as prediction of patient outcomes and therapeutic responses.

\section{Staging of Regional Lymph Nodes}

Preoperative determination of involvement of regional lymph nodes can influence the selection of treatment options. For patients with T1 and T2 breast cancer, a positive cytologic diagnosis avoids unnecessary sentinel lymph node 
procedures (Fig. 1A, B) [32, 33]. For patients with locally advanced breast cancer, a positive regional lymph node status is prognostic of treatment failure and provides a baseline for monitoring therapeutic response [34].

Neither physical examination or imaging is sensitive or reliable in assessing lymph node involvement by metastatic disease [35]. Tissue biopsy is necessary to accurately determine nodal status. FNAB with or without imaging guidance has been widely adopted for this purpose. Inadequate samples are reported in less than $10 \%$ of cases with on-site assessment of adequacy [36-38]. The overall sensitivity and specificity of ultrasound-guided FNAB for the evaluation of axillary lymph nodes for preoperative staging of breast cancer range from $25 \%$ to $95 \%$ and from $97 \%$ to $100 \%$, respectively $[35,37,39-44]$. False positive diagnoses are rare, less than $2 \%[37,44,45]$. The common causes of false-negative results include sampling error, small metastases $(<5 \mathrm{~mm})$, involvement of few $(<3)$ lymph nodes, and interpretive errors [46].

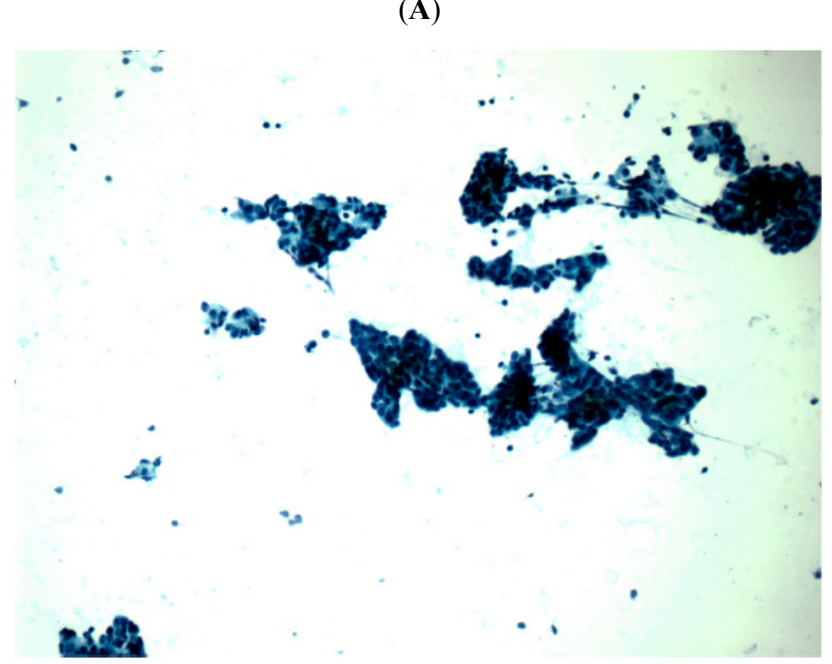

(B)

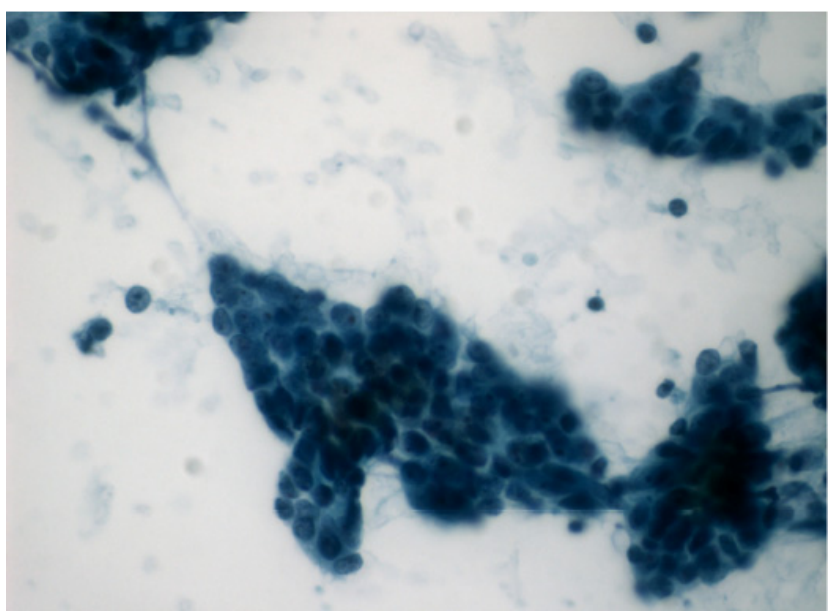

Fig. (1). FNAB of axillary lymph node, low-power showing a cellular smear with numerous clusters of epithelial tumor cells with angular configuration in a background of scant lymphocytes (Papanicolaou stain $20 \mathrm{X}$ ) (A). Higher magnification showing pleomorphic population of tumor cells with high nuclear grade with clumped chromatin and conspicuous nucleoli (Papanicolaou stain 40x) (B).

\section{Other Indications for FNAB}

In addition to being a diagnostic tool, FNAB has also been utilized to collect breast tissue for monitoring of therapeutic response of women receiving neoadjuvant chemotherapy and for risk assessment in asymptomatic women without suspicious lesions on physical examination or mammography.

Serial FNAB: Preoperative neoadjuvant chemotherapy is the standard of care in locally advanced breast cancer with the intention to expand surgical options and to improve survival. The extent of tumor response to neoadjuvant chemotherapy correlates with disease free and overall survival [47-50]. Modification of their treatment regimes may be warranted if patients who are expected to have no or partial response could be identified early. Taking a series of FNABs of a tumor during the course of therapy can provide useful information about treatment-induced changes in biomarkers, which in turn may be helpful in monitoring patient response to neoadjuvant chemotherapy [51-53]. For example, a decrease in proliferation indices as measured by $\mathrm{Ki}-67$ and an increase in Bcl-2 expression in serial FNAB taken after 21 days of neoadjuvant chemotherapy consisting of mitoxantrone and methotrexate correlated with complete response in patients with primary breast cancer [52]. More recently, based on FNAB-derived cDNA microarray expression profiling, the number of genes that changes after one cycle of neoadjuvant chemotherapy (adriamycin and cyclophospamide) was 10 times greater in tumors with complete response than those with partial or no response [53].

Random Periareolar Fine Needle Aspiration (RPFNA): RPFNA consists of aspirating 2 random sites approximately $1 \mathrm{~cm}$ from the nipple areolar complex in both the upper-outer and upper-inner quadrants of each breast [54]. The premise of RPFNA is based on the belief that random tissue sampling may be able to detect proliferative changes associated with increased breast cancer risk if these changes are widespread within the breast [55]. When 4 to 5 passes were taken per site, adequate cytology for morphologic assessment was achieved in $94 \%$ of women [54]. Asymptomatic women who were found to have cytologic atypia on RPFNA were more likely to develop carcinoma than those without atypia within 3 years [54]. Limitations of RPFNA include intra- and interobserver variation and inability to precisely locate an area of severe atypia.

\section{TOUCH PREPARATION}

Touch preparation (TP) cytology, also known as imprint cytology, consists of smearing fresh tissue onto a glass slide which is then stained. There has been great interest recently in the use of TP cytology in the management of breast cancer patients. Some examples include intraoperative evaluation of sentinel lymph nodes and surgical margins of lumpectomy specimens, as well as the provision of immediate assessment of CNB.

\section{Breast Core Needle Biopsies}

As mentioned earlier, CNB has gradually replaced FNAB as the diagnostic procedure of choice for patients with breast lesions. However, patients and physicians must traditionally 
(A)

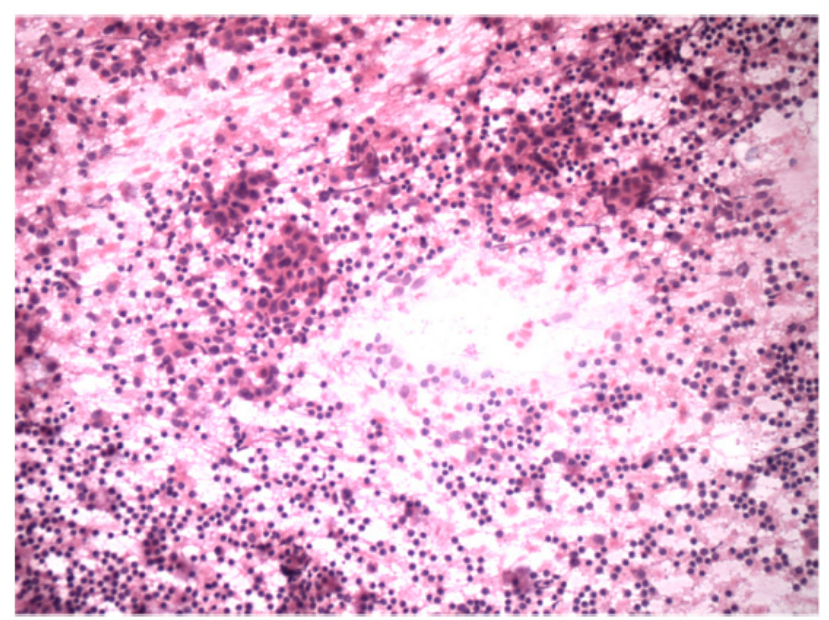

(B)

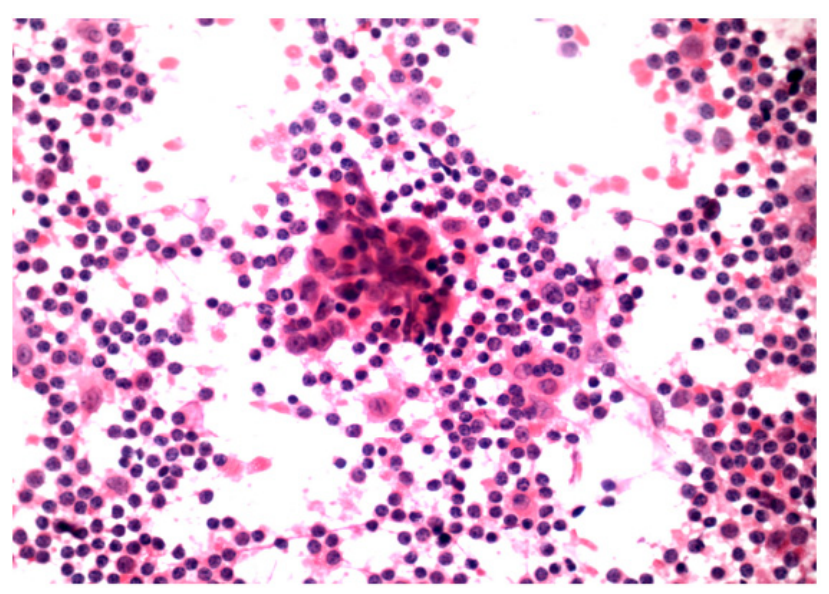

(C)

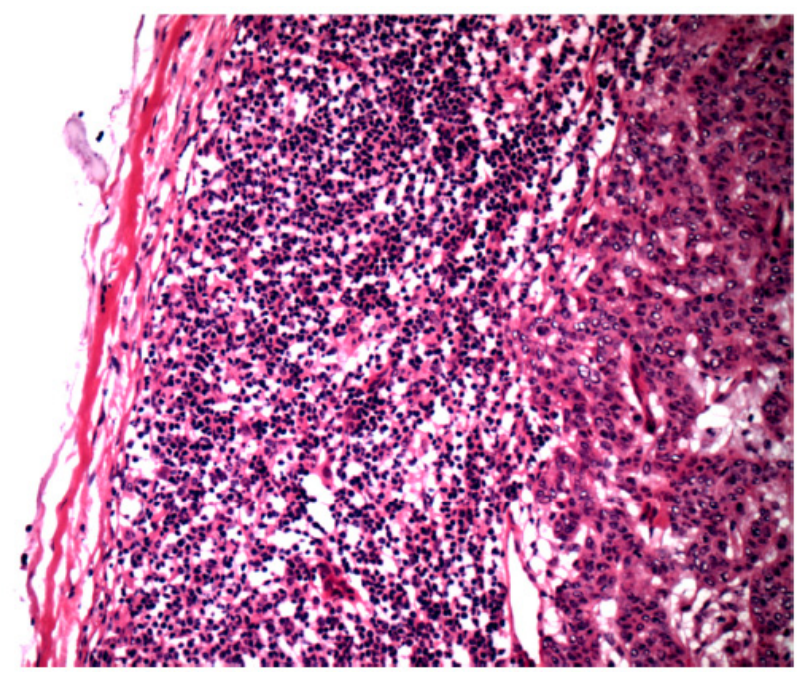

Fig. (2). Touch preparation of a sentinel lymph node, low-power showing loosely cohesive groups and clusters of tumor cells in a background of numerous small lymphoctes (H\&E 20X), (A). Higher magnification showing an irregular cluster of tumor cells with large epithelial cells that display increased nuclear to cytoplasmic ratio and prominent nucleoli (40X) (B). Frozen section of lymph node showing sheets of epithelial tumor cells surrounded by lymphocytes consistent with metastatic breast carcinoma $(\mathbf{C})$. wait a day or two for the final diagnosis, resulting in patient anxiety, an additional clinic visit, and delays in operative scheduling. To overcome this limitation, TP cytology has been evaluated as an improved means for offering same-day diagnosis for CNB. It has been shown that the sensitivity and specificity of TP cytology range from $75 \%$ to $95 \%$ and from $95 \%$ to $98 \%$, respectively [56-59]. The frequency of inadequate TP cytology varies widely, from 0 to $29 \%$, and is similar to that of FNAB [56, 59-61]. Although both false positive and false negative preliminary diagnoses should be avoided at all cost, a false positive diagnosis potentially results in greater upset to the patients. Therefore, like FNAB, one should apply the triple test to minimize both false negatives and false positives; if there is any discrepancy between the cytologic findings and the clinical or radiologic findings, one should defer to permanent histology for final diagnosis. It is important to remember that TP cytology should not replace permanent histological evaluation.

\section{Intraoperative Assessment of Sentinel Lymph Nodes}

Evaluation of sentinel lymph nodes for the presence of metastatic disease has become a standard practice for management of breast cancer patients worldwide. The objective is to avoid unnecessary axillary nodal dissection for up to $70 \%$ of women with early breast cancer [62]. Intraoperative consultation is often preformed at the time of sentinel node biopsy in order to avoid the additional morbidity and cost of a second, separate operation. Although frozen sectioning is often used in intraoperative consultation, the process of freezing, then thawing, results in artifacts and tissue loss that may impact negatively on subsequent permanent pathological evaluation. TP cytology has been shown to be a viable alternative for intraoperative evaluation of sentinel node status. Compared to frozen sectioning, TP cytology is less expensive, less labor intensive, less technically challenge, and less time consuming. In addition, TP cytology enables the preservation of the full architecture of the tissue samples for permanent pathological evaluation. According to a recent meta-analysis of sentinel node TP cytology in breast cancer, the authors reported a pooled sensitivity of $63 \%$ and specificity of $99 \%$; the respective values for frozen sections were $76 \%$ and $99 \%$ [63] (Fig. 2A-C). The apparent lower sensitivity of TP cytology when compared to frozen sectioning may be a function of the size of the metastasis; the pooled sensitivity of TP cytology for macrometastases was $81 \%$ and that for micrometastases (defined as $<2 \mathrm{~mm}$ or detected only by immunohistochemistry) was $22 \%$ [63]. The impact of not detecting micrometastatic disease in patients with early breast cancer remains unknown; however, some authors have advocated that axillary nodal dissection may not be indicated when only micrometastatic disease is found on sentinel node examination [64]. A potential pitfall of TP cytology is the detection of metastases from lobular carcinomas that may resemble benign cells and are not infrequently scattered throughout a lymph node, although no significant differences in diagnostic accuracy was reported for lobular carcinoma versus ductal carcinoma [65].

\section{Intraoperative Assessment of Surgical Margins of Lump- ectomy Specimens}

Breast conservation surgery in combination with radiotherapy is standard treatment for the majority of breast cancers. The presence of microscopic residual disease at 
margins accounts for up to $25 \%$ local recurrence as compared to less than $4 \%$ local recurrence in patients with negative margins; [66-70] therefore, obtaining clear margins is critical to minimize local recurrence. TP cytology of the margins of lumpectomy specimens has been shown to rapidly and reliably evaluate margins with a diagnostic accuracy ranging from $73 \%$ to $100 \%$ [71-73]. The advantages of TP cytology over frozen sections include avoidance of problems associated with freezing and cutting adipose tissue as well as the ability to evaluate the entire marginal surface area of the resected specimens.

\section{NIPPLE FLUID CYTOLOGY}

Nipple discharge is relatively uncommon and can be due to either physiologic or pathologic conditions; the latter is most commonly associated with intraductal papillomas (Fig. 3). About $10 \%$ of patients with nipple discharge are found to have an underlying malignancy [74]. In general, nipple discharge fluid cytology is considered to be an ineffective diagnostic tool. Recent studies reported that the sensitivity and specificity of nipple discharge fluid cytology in diagnosing malignancy range from $16 \%$ to $46 \%$ and from $60 \%$ to $62 \%$, respectively $[75,76]$.

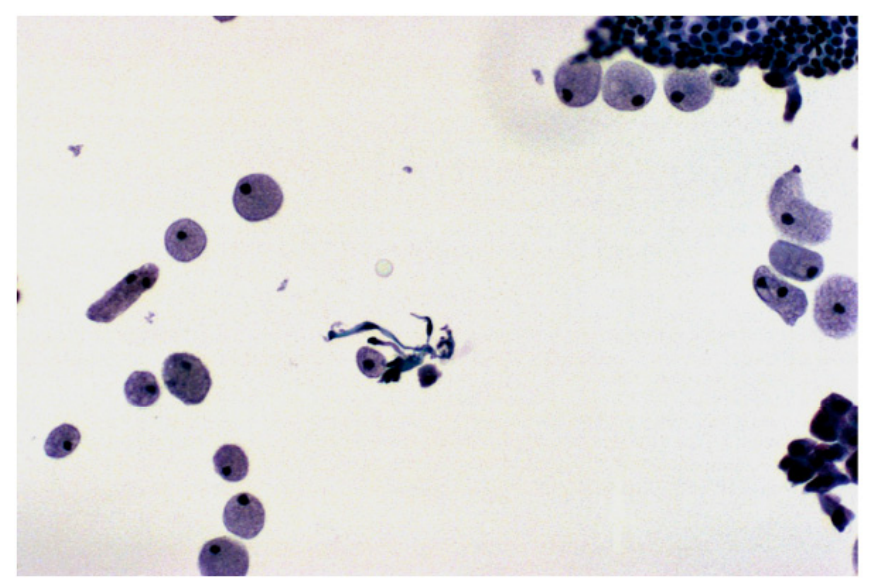

Fig. (3). Nipple discharge specimen showing numerous foamy macrophages and few ductal epithelial cells suggestive of benign cyst (Papanicolaou stain $20 \mathrm{X}$ ).

Attempts have been made to obtain nipple secretions from massaging/pumping the breast or by aspirating the nipple from asymptomatic women for the purpose of breast cancer screening. In a mass screening study using nipple fluids obtained from breast massage, only $0.1 \%$ of 150,000 Japanese women were found to have malignancy [77]. Similarly, nipple fluid aspiration also has a low sensitivity of detection of breast cancer; cancer cells were demonstrated in less than half of the nipple aspirate fluids obtained from patients who underwent breast cancer surgery [78-80]. Therefore, nipple aspirate fluid (NAF) cytology is of limited use in the current clinical setting.

\section{DUCTAL LAVAGE}

Ductal lavage (DL) was introduced in the last decade as a minimally invasive procedure to identify cellular atypia in mammary ducts. The underlying premise is that the presence of atypical ductal cells is predictive of increased risk of developing breast cancer [81, 82]. DL, as an individualized assessment tool, is Food and Drug Administration (FDA)- approved only for women who are at an increased risk for developing breast carcinoma but without suspicious lesions on physical examination or mammography.

DL yields far more cells, with a median number of 13,500 versus 120 cells, when compared to NAF samples; about $80 \%$ of samples were classified as adequate [83]. Based on the degree of cytologic atypia, DL specimens can be classified as benign, mild atypia, marked atypia, and malignant [84]. When DL demonstrates unequivocal malignant cells, further investigation, such as magnetic resonance imaging, is warranted to localize any occult lesions. However, several studies have reported low sensitivity of DL in detecting breast carcinoma in patients undergoing mastectomy for carcinoma $[85,86]$. A plausible explanation is that DL only samples cells from intraductal processes; about 15 to $30 \%$ of invasive cancers lack an intraductal components $[87,88]$. For DL specimens with atypia below the level of malignancy, the clinical significance of such findings is not known. A wide variety of benign conditions such as papilloma, fibroadenoma, duct ectasia, and endogenous and iatrogenic hormonal states, can give rise to varying degrees of atypia, resulting in poor correlation of the degree of cytologic abnomarlitie with various proliferative breast disease [84]. Furthermore, there is poor interobserver reproducibility in interpretation of DL specimens among pathologists [84].

Currently, DL is not considered a screening tool for the general population. One reason is that it is not FDAapproved for women who have no known risk factors, the group that would most benefit from such a risk assessment tool. Another disadvantage of DL is that both clinicians and pathologists have to undergo training to be able to perform the procedure and interpret the findings, respectively. Even for women who are at high risk for developing breast cancer, DL is only one of the few diagnostic tools for individualized risk assessment and should not be construed as a substitute for more established means of diagnosis such as clinical examination and mammography.

\section{CIRCULATING TUMOR CELLS}

The detection of circulating tumor cells (CTCs) in the peripheral blood is one of the newest tools in the management of many human cancers including breast cancer. A variety of methods have been developed to detect CTCs in peripheral blood. However, to date, the only FDA-approved method for detection of CTCs in patients with metastatic breast, colon, and prostate cancers is the CellSearch System (Veridex, Raritan, NJ) which combines cytomorphology and immunology for the detection of CTCs. Briefly, using antibody coated magnetic beads, the CellSearch System captures circulating cells expressing epithelial cell adhesion molecule (EpCAM). The captured cells are then labeled with fluorescent monoclonal antibodies specific for leukocytes (CD45) and epithelial cells (CK 8, 18, and 19). Fluorescent marker-labeled circulating cells are then displayed on the computer screen with the aid of an automated microscope. CTCs are defined as $\mathrm{CK}+/ \mathrm{CD} 45-$ nucleated cells. High interobserver agreement and high instrument reproducibility are noted $[89,90]$.

Based on a large cohort of breast cancer patients, a high CTC count measured using the CellSearch assay at the time 
of diagnosis was found to be an independent adverse prognostic factor [91]. In addition, the same study also demonstrated that after the completion of chemotherapy, disease progression was inevitable in patients with metastatic breast cancer if the initial positive CTC assay failed to fall below 5 cells per $7.5 \mathrm{ml}$ of blood [91]. The latter observation suggests that the CTC assay by CellSearch may be helpful in monitoring therapeutic response. Tumor cells derived from the so-called "normal genotype" of invasive breast carcinoma are typically negative for EpCAM expression and may constitute a false negative interpretation [92].

\section{MOLECULAR ANALYSIS AND BREAST CYTOLOGY}

With the advent of molecular technologies, abundant evidence has emerged to support the notion that each patient's breast cancer possesses a unique molecular signature that may impart prognostic significance and influence therapeutic decisions [93-95]. For example, it has been shown that gene expression profiles are more powerful than traditional clinico-pathologic parameters in predicting disease outcomes in young patients with breast cancers [93]. Gene expression profiling can also be helpful in identifying patients who would not benefit from chemotherapy, avoiding exposure to the toxicities and risks of such treatment [96]. Therefore, comprehensive molecular profiling would influence our understanding of the classification, prognosis, and therapeutic response of breast cancers.

Several studies have shown that $70 \%$ (based on a single pass) to $100 \%$ (based on 3 to 4 passes) of FNAB aspirates can yield a sufficient amount ( $>1$ ug) of mRNA for molecular testing such as cDNA microarray analyses [31, 97, 98]. Symmans et al. demonstrated that transcriptional profiles from $\mathrm{FNAB}$ and $\mathrm{CNB}$ of the same tumors were generally similar [31]. A few years later, the same group of investigators were able to separate ER-negative and ERpositive tumors based on gene expression profiles obtained from FNAB of breast cancers [99].

FNAB samples can also been used for proteomic analyses. Using surface enhanced laser desorption-ionization time of flight (SELDI-TOF) methodology, similar reproducible protein profiles were noted for the majority of FNAB from various benign breast lesions whereas protein profiles obtained from the aspirates of malignant lesions were visually different from those of benign breast lesions as well as between different subtypes of carcinomas [100]. In a more recent study, cellular samples derived from archival cytology aspirate smears and frozen FNAB samples were subjected to reverse phase protein microarray (RPPM) technology [101] Adequate amounts of protein were extracted from both preparations to allow the quantification of individual phospholyated and nonphosphorylated proteins. Potential applications of RPPM include in vivo monitoring of cell-signaling proteins before and after treatment, thus enhancing the ability to prescribe individualized therapy regimens through the mapping of aberrant cell-signaling patterns [101].

Molecular testing can also be used to aid in the assessment of the short-term risk of developing breast cancer. Current risk models, such as the Gail Model, which are based on personal and family history, have only limited individual discriminatory value [102] Increasing attention has been given to the use of risk biomarkers to improve short-term predictive accuracy for the individual woman who is at risk of developing breast cancer and who may benefit from medical or surgical prevention options. Although cytomorphology may have limited value as a risk factor, breast fluids and aspirates obtained through NAF, DL, or RPFNA in asymptomatic women can provide a rich source of biomarkers for risk assessment. A sufficient amount of RNA can be made available from RPFNA samples for quantitative polymerase chain reaction (PCR) for 6 to 12 biomarkers [103] Recently, it has been shown that quantitative evaluation of DNA hypermethylation using methylation-specific PCR can be readily preformed on NAF and DL samples [104] These authors observed that methylation of CCND-2, p16, RAR-beta, and RASSF-1a was significantly more prevalent in tumor than in normal tissue specimens. In another study, using fluorescent in situ hybridization, chromosomal alterations identified in DL specimens obtained from women who underwent breast cancer surgery matched those identified in the corresponding resected breast cancers using comparative genomic hybridization [105]. Interestingly, only $10 \%$ of the DL samples were identified as malignant cytologically, whereas over half of the DL samples showed molecular changes characteristic of the tumor.

\section{CONCLUSIONS}

Breast cytology continues to play an integral part in the management of beast lesions. In experienced hands, FNAB is reliable and accurate for diagnosing breast cancers. One major obstacle is the challenge to provide suitable materials for meeting the current guidelines for the quantitative evaluation of HER2 expression. In addition to its role as a diagnostic tool, breast cytology has gradually established itself as an individual risk assessment tool for women at risk of developing breast cancer and a reliable alternative to frozen sectioning during intraoperative evaluation of sentinel lymph nodes and margins of lumpectomay specimens. With the rapid increase in the diversity and utilization of molecular technologies, many investigators have demonstrated the feasibility of applying genomic and proteomic studies to breast cytology. It would not be far fetched to predict that the clinical application of molecular analyses to cytologic samples of the breast will be routine in the near future.

\section{REFERENCES}

[1] Britton PD, Flower CD, Freeman AH, et al. Changing to core biopsy in an NHS breast screening unit. Clin Radiol 1997; 52(10): 764-7.

[2] Cobb CJ, Raza AS. Obituary: "alas poor FNA of breast-we knew thee well!". Diagn Cytopathol 2005; 32(1): 1-4.

[3] Gordon PB. Image-directed fine needle aspiration biopsy in nonpalpable breast lesions. Clin Lab Med 2005; 25(4): 655-78.

[4] Hussain MT. Comparison of fine needle aspiration cytology with excision biopsy of breast lump. J Coll Physicians Surg Pak 2005; 15(4): 211-4.

[5] Mizuno S, Isaji $\mathrm{S}$, Ogawa $\mathrm{T}$, et al. Approach to fine-needle aspiration cytology-negative cases of breast cancer. Asian J Surg 2005; 28(1): 13-7.

[6] Mohammed AZ, Edino ST, Ochicha O, Alhassan SU. Value of Fine Needle Aspiration Biopsy in Preoperative Diagnosis of Palpable Breast Lumps in Resource-Poor Countries: A Nigerian Experience. Annals of African Medicine 2005; 4(1): 19-22. 
[7] Orell SR, Miliauskas J. Fine needle biopsy cytology of breast lesions: a review of interpretative difficulties. Adv Anat Pathol 2005; 12(5): 233-45.

[8] Zagorianakou P, Fiaccavento S, Zagorianakou N, Makrydimas G, Stefanou D, Agnantis NJ. FNAC: its role, limitations and perspective in the preoperative diagnosis of breast cancer. Eur $\mathrm{J}$ Gynaecol Oncol 2005; 26(2): 143-9.

[9] Bulgaresi P, Cariaggi P, Ciatto S, Houssami N. Positive predictive value of breast fine needle aspiration cytology (FNAC) in combination with clinical and imaging findings: a series of 2334 subjects with abnormal cytology. Breast Cancer Res Treat 2006; 97(3): 319-21.

[10] Chaiwun B, Settakorn J, Ya-In C, Wisedmongkol W, Rangdaeng S, Thorner P. Effectiveness of fine-needle aspiration cytology of breast: analysis of 2,375 cases from northern Thailand. Diagn Cytopathol 2002; 26(3): 201-5.

[11] Ellis EB, Martin HE. Aspiration Biopsy. Surg Gynecol Obstret 1934; 59: 578-89.

[12] Chaiwun B, Thorner P. Fine needle aspiration for evaluation of breast masses. Curr Opin Obstet Gynecol 2007; 19(1): 48-55.

[13] Ariga R, Bloom K, Reddy VB, et al. Fine-needle aspiration of clinically suspicious palpable breast masses with histopathologic correlation. Am J Surg 2002; 184(5): 410-3.

[14] Sneige N. Fine-needle aspiration of the breast: a review of 1,995 cases with emphasis on diagnostic pitfalls. Diagn Cytopathol 1993; 9(1): 106-12.

[15] Ballo MS, Sneige N. Can core needle biopsy replace fine-needle aspiration cytology in the diagnosis of palpable breast carcinoma. A comparative study of 124 women. Cancer 1996; 78(4): 773-7.

[16] Boerner S, Fornage BD, Singletary E, Sneige N. Ultrasound-guided fine-needle aspiration (FNA) of nonpalpable breast lesions: a review of 1885 FNA cases using the National Cancer Institutesupported recommendations on the uniform approach to breast FNA. Cancer 1999; 87(1): 19-24.

[17] Fajardo LL, Pisano ED, Caudry DJ, et al. Stereotactic and sonographic large-core biopsy of nonpalpable breast lesions: results of the Radiologic Diagnostic Oncology Group V study. Acad Radiol 2004; 11(3): 293-308.

[18] Day C, Moatamed N, Fimbres AM, Salami N, Lim S, Apple SK. A retrospective study of the diagnostic accuracy of fine-needle aspiration for breast lesions and implications for future use. Diagn Cytopathol 2008; 36(12): 855-60.

[19] Lau SK, McKee GT, Weir MM, Tambouret RH, Eichhorn JH, Pitman MB. The negative predicative value of breast fine-needle aspiration biopsy: the Massachusetts General Hospital experience. Breast J 2004; 10(6): 487-91.

[20] Shin HJ, Sneige N. Is a diagnosis of infiltrating versus in situ ductal carcinoma of the breast possible in fine-needle aspiration specimens? Cancer 1998; 84(3): 186-91.

[21] McKee GT, Tambouret RH, Finkelstein D. Fine-needle aspiration cytology of the breast: Invasive $v s$. in situ carcinoma. Diagn Cytopathol 2001; 25(1): 73-7.

[22] Sauer T, Young K, Thoresen SO. Fine needle aspiration cytology in the work-up of mammographic and ultrasonographic findings in breast cancer screening: an attempt at differentiating in situ and invasive carcinoma. Cytopathology 2002; 13(2): 101-10.

[23] King TA, Farr GH, Cederbom GJ, et al. A mass on breast imaging predicts coexisting invasive carcinoma in patients with a core biopsy diagnosis of ductal carcinoma in situ. Am Surg 2001; 67(9): 907-12.

[24] Hoorntje LE, Schipper ME, Peeters PH, Bellot F, Storm RK, Borel Rinkes IH. The finding of invasive cancer after a preoperative diagnosis of ductal carcinoma-in situ: causes of ductal carcinomain situ underestimates with stereotactic 14-gauge needle biopsy. Ann Surg Oncol 2003; 10(7): 748-53.

[25] Debono SE, Lashbrook B, McCracken S, Moriaty AT. Thereis no need to use core biopsy to confirm invasion in breast cancer. Acta Cytologica 1995; 39(5): 1013

[26] Chhieng DC, Fernandez G, Cangiarella JF, et al. Invasive carcinoma in clinically suspicious breast masses diagnosed as adenocarcinoma by fine-needle aspiration. Cancer 2000; 90(2): 96101.

[27] Nasuti JF, Gupta PK, Baloch ZW. Diagnostic value and costeffectiveness of on-site evaluation of fine-needle aspiration specimens: review of 5,688 cases. Diagn Cytopathol 2002; 27(1): $1-4$.
[28] Layfield LJ, Bentz JS, Gopez EV. Immediate on-site interpretation of fine-needle aspiration smears: a cost and compensation analysis. Cancer 2001; 93(5): 319-22

[29] Wolff AC, Hammond ME, Schwartz JN, et al. American Society of Clinical Oncology/College of American Pathologists guideline recommendations for human epidermal growth factor receptor 2 testing in breast cancer. Arch Pathol Lab Med 2007; 131(1): 18-43.

[30] Williams SL, Birdsong GG, Cohen C, Siddiqui MT. Immunohistochemical detection of estrogen and progesterone receptor and HER2 expression in breast carcinomas: comparison of cell block and tissue block preparations. Int J Clin Exp Pathol 2009; 2(5): 476-80.

[31] Symmans WF, Ayers M, Clark EA, et al. Total RNA yield and microarray gene expression profiles from fine-needle aspiration biopsy and core-needle biopsy samples of breast carcinoma. Cancer 2003; 97(12): 2960-71.

[32] Giuliano AE, Kirgan DM, Guenther JM, Morton DL. Lymphatic mapping and sentinel lymphadenectomy for breast cancer. Ann Surg 1994; 220(3): 391-8; discussion 8-401.

[33] Veronesi U, Paganelli G, Galimberti V, et al. Sentinel-node biopsy to avoid axillary dissection in breast cancer with clinically negative lymph-nodes. Lancet 1997; 349(9069): 1864-7.

[34] Kilbride KE, Lee MC, Nees AV, et al. Axillary staging prior to neoadjuvant chemotherapy for breast cancer: predictors of recurrence. Ann Surg Oncol 2008; 15(11): 3252-8.

[35] Alvarez S, Anorbe E, Alcorta P, Lopez F, Alonso I, Cortes J. Role of sonography in the diagnosis of axillary lymph node metastases in breast cancer: a systematic review. AJR Am J Roentgenol 2006; 186(5): 1342-8.

[36] Deurloo EE, Tanis PJ, Gilhuijs KG, et al. Reduction in the number of sentinel lymph node procedures by preoperative ultrasonography of the axilla in breast cancer. Eur J Cancer 2003; 39(8): 1068-73.

[37] Ciatto S, Brancato B, Risso G, et al. Accuracy of fine needle aspiration cytology (FNAC) of axillary lymph nodes as a triage test in breast cancer staging. Breast Cancer Res Treat 2007; 103(1): 8591.

[38] Sapino A, Cassoni P, Zanon E, et al. Ultrasonographically-guided fine-needle aspiration of axillary lymph nodes: role in breast cancer management. Br J Cancer 2003; 88(5): 702-6.

[39] Alkuwari E, Auger M. Accuracy of fine-needle aspiration cytology of axillary lymph nodes in breast cancer patients: a study of 115 cases with cytologic-histologic correlation. Cancer 2008; 114(2): 89-93.

[40] Sahoo S, Sanders MA, Roland L, Pile N, Chagpar AB. A strategic approach to the evaluation of axillary lymph nodes in breast cancer patients: analysis of 168 patients at a single institution. Am J Surg 2007; 194(4): 524-6.

[41] Hinson JL, McGrath P, Moore A, et al. The critical role of axillary ultrasound and aspiration biopsy in the management of breast cancer patients with clinically negative axilla. Ann Surg Oncol 2008; 15(1): 250-5.

[42] Koelliker SL, Chung MA, Mainiero MB, Steinhoff MM, Cady B. Axillary lymph nodes: US-guided fine-needle aspiration for initial staging of breast cancer--correlation with primary tumor size. Radiology 2008; 246(1): 81-9.

[43] Jain A, Haisfield-Wolfe ME, Lange J, et al. The role of ultrasoundguided fine-needle aspiration of axillary nodes in the staging of breast cancer. Ann Surg Oncol 2008; 15(2): 462-71.

[44] van Rijk MC, Deurloo EE, Nieweg OE, et al. Ultrasonography and fine-needle aspiration cytology can spare breast cancer patients unnecessary sentinel lymph node biopsy. Ann Surg Oncol 2006; 13(1): 31-5.

[45] Kuenen-Boumeester V, Menke-Pluymers M, de Kanter AY, Obdeijn IM, Urich D, Van Der Kwast TH. Ultrasound-guided fine needle aspiration cytology of axillary lymph nodes in breast cancer patients. A preoperative staging procedure. Eur J Cancer 2003; 39(2): 170-4.

[46] Krishnamurthy S. Current applications and future prospects of fineneedle aspiration biopsy of locoregional lymph nodes in the management of breast cancer. Cancer Cytopathol 2009; 117(6): 451-62.

[47] Hortobagyi GN, Ames FC, Buzdar AU, et al. Management of stage III primary breast cancer with primary chemotherapy, surgery, and radiation therapy. Cancer 1988; 62(12): 2507-16. 
[48] Bonadonna G, Valagussa P, Brambilla C, et al. Primary chemotherapy in operable breast cancer: eight-year experience at the Milan Cancer Institute. J Clin Oncol 1998; 16(1): 93-100.

[49] Machiavelli MR, Romero AO, Perez JE, et al. Prognostic significance of pathological response of primary tumor and metastatic axillary lymph nodes after neoadjuvant chemotherapy for locally advanced breast carcinoma. Cancer J Sci Am 1998; 4(2): 125-31.

[50] Kuerer HM, Newman LA, Smith TL, et al. Clinical course of breast cancer patients with complete pathologic primary tumor and axillary lymph node response to doxorubicin-based neoadjuvant chemotherapy. J Clin Oncol 1999; 17(2): 460-9.

[51] Symmans WF, Volm MD, Shapiro RL, et al. Paclitaxel-induced apoptosis and mitotic arrest assessed by serial fine-needle aspiration: implications for early prediction of breast cancer response to neoadjuvant treatment. Clin Cancer Res 2000; 6(12): 4610-7.

[52] Chang J, Powles TJ, Allred DC, et al. Biologic markers as predictors of clinical outcome from systemic therapy for primary operable breast cancer. J Clin Oncol 1999; 17(10): 3058-63.

[53] Sotiriou C, Powles TJ, Dowsett M, et al. Gene expression profiles derived from fine needle aspiration correlate with response to systemic chemotherapy in breast cancer. Breast Cancer Res 2002; 4(3): R3.

[54] Fabian CJ, Kimler BF, Zalles CM, et al. Short-term breast cancer prediction by random periareolar fine-needle aspiration cytology and the Gail risk model. J Natl Cancer Inst 2000; 92(15): 1217-27.

[55] Fabian CJ, Kimler BF, Mayo MS, Khan SA. Breast-tissue sampling for risk assessment and prevention. Endocr Relat Cancer 2005; 12(2): 185-213.

[56] Kass R, Henry-Tillman RS, Nurko J, et al. Touch preparation of breast core needle specimens is a new method for same-day diagnosis. Am J Surg 2003; 186(6): 737-41; discussion 42.

[57] Jacobs TW, Silverman JF, Schroeder B, Raza S, Baum JK, Schnitt SJ. Accuracy of touch imprint cytology of image-directed breast core needle biopsies. Acta Cytol 1999; 43(2): 169-74.

[58] Green RS, Mathew S. The contribution of cytologic imprints of stereotactically guided core needle biopsies of the breast in the management of patients with mammographic abnormalities. Breast J 2001; 7(4): 214-8.

[59] March DE, Walker MT, Bur M, et al. Touch-preparation cytologic examination of breast core biopsy specimens: accuracy in predicting benign or malignant core histologic results. Acad Radiol 1999; 6(6): 333-8

[60] Albert US, Duda V, Hadji P, et al. Imprint cytology of core needle biopsy specimens of breast lesions. A rapid approach to detecting malignancies, with comparison of cytologic and histopathologic analyses of 173 cases. Acta Cytol 2000; 44(1): 57-62.

[61] Sneige N, Tulbah A. Accuracy of cytologic diagnoses made from touch imprints of image-guided needle biopsy specimens of nonpalpable breast abnormalities. Diagn Cytopathol 2000; 23(1): 29-34.

[62] Miltenburg DM, Miller C, Karamlou TB, Brunicardi FC. Metaanalysis of sentinel lymph node biopsy in breast cancer. J Surg Res 1999; 84(2): 138-42.

[63] Tew K, Irwig L, Matthews A, Crowe P, Macaskill P. Meta-analysis of sentinel node imprint cytology in breast cancer. Br J Surg 2005; 92(9): 1068-80.

[64] Grube BJ, Giuliano AE. Observation of the breast cancer patient with a tumor-positive sentinel node: implications of the ACOSOG Z0011 trial. Semin Surg Oncol 2001; 20(3): 230-7.

[65] Creager AJ, Geisinger KR, Perrier ND, et al. Intraoperative imprint cytologic evaluation of sentinel lymph nodes for lobular carcinoma of the breast. Ann Surg 2004; 239(1): 61-6.

[66] Smitt MC, Nowels KW, Zdeblick MJ, et al. The importance of the lumpectomy surgical margin status in long-term results of breast conservation. Cancer 1995; 76(2): 259-67.

[67] Singletary SE. Surgical margins in patients with early-stage breast cancer treated with breast conservation therapy. Am J Surg 2002; 184(5): 383-93.

[68] Heimann R, Powers C, Halpem HJ, et al. Breast preservation in stage I and II carcinoma of the breast. The University of Chicago experience. Cancer 1996; 78(8): 1722-30.

[69] DiBiase SJ, Komarnicky LT, Schwartz GF, Xie Y, Mansfield CM. The number of positive margins influences the outcome of women treated with breast preservation for early stage breast carcinoma. Cancer 1998; 82(11): 2212-20.

[70] Mansfield CM, Komarnicky LT, Schwartz GF, et al. Ten-year results in 1070 patients with stages I and II breast cancer treated by conservative surgery and radiation therapy. Cancer $1995 ; 75(9)$ : 2328-36.

[71] Saarela AO, Paloneva TK, Rissanen TJ, Kiviniemi HO Determinants of positive histologic margins and residual tumor after lumpectomy for early breast cancer: a prospective study with special reference to touch preparation cytology. J Surg Oncol 1997; 66(4): 248-53

[72] Cox CE, Ku NN, Reintgen DS, Greenberg HM, Nicosia SV, Wangensteen S. Touch preparation cytology of breast lumpectomy margins with histologic correlation. Arch Surg 1991; 126(4): 4903.

[73] Creager AJ, Shaw JA, Young PR, Geisinger KR. Intraoperative evaluation of lumpectomy margins by imprint cytology with histologic correlation: a community hospital experience. Arch Pathol Lab Med 2002; 126(7): 846-8.

[74] Masood S, Khalbuss WE. Nipple fluid cytology. Clin Lab Med 2005; 25(4): 787-94, vii-viii.

[75] Kooistra BW, Wauters C, van de Ven S, Strobbe L. The diagnostic value of nipple discharge cytology in 618 consecutive patients. Eur J Surg Oncol 2009; 35(6): 573-7.

[76] Carvalho MJ, Dias M, Goncalo M, Fernandes G, Rodrigues V, de Oliveira CF. What is the diagnostic value of nipple discharge cytology and galactography in detecting duct pathology? Eur J Gynaecol Oncol 2009; 30(5): 543-6.

[77] Takeda T, Matsui A, Sato Y, et al. Nipple discharge cytology in mass screening for breast cancer. Acta Cytol 1990; 34(2): 161-4.

[78] King EB, Chew KL, Petrakis NL, Ernster VL. Nipple aspirate cytology for the study of breast cancer precursors. J Natl Cancer Inst 1983; 71(6): 1115-21.

[79] Sauter ER, Klein-Szanto A, Macgibbon B, Ehya H. Nipple aspirate fluid and ductoscopy to detect breast cancer. Diagn Cytopathol 2009; 38(4): 244-51.

[80] Sauter ER, Ross E, Daly M, et al. Nipple aspirate fluid: a promising non-invasive method to identify cellular markers of breast cancer risk. Br J Cancer 1997; 76(4): 494-501.

[81] Wrensch MR, Petrakis NL, King EB, et al. Breast cancer incidence in women with abnormal cytology in nipple aspirates of breast fluid. Am J Epidemiol 1992; 135(2): 130-41.

[82] Page DL, Dupont WD. Anatomic indicators (histologic and cytologic) of increased breast cancer risk. Breast Cancer Res Treat 1993; 28(2): 157-66

[83] Dooley WC, Ljung BM, Veronesi U, et al. Ductal lavage for detection of cellular atypia in women at high risk for breast cancer. J Natl Cancer Inst 2001; 93(21): 1624-32.

[84] Masood S. Cytomorphology as a risk predictor: experience with fine needle aspiration biopsy, nipple fluid aspiration, and ductal lavage. Clin Lab Med 2005; 25(4): 827-43, viii-ix.

[85] Brogi E, Robson M, Panageas KS, Casadio C, Ljung BM, Montgomery L. Ductal lavage in patients undergoing mastectomy for mammary carcinoma: a correlative study. Cancer 2003; 98(10): 2170-6.

[86] Khan SA, Wiley EL, Rodriguez N, et al. Ductal lavage findings in women with known breast cancer undergoing mastectomy. J Natl Cancer Inst 2004; 96(20): 1510-7.

[87] Badve S, Wiley E, Rodriguez N. Assessment of utility of ductal lavage and ductoscopy in breast cancer-a retrospective analysis of mastectomy specimens. Mod Pathol 2003; 16(3): 206-9.

[88] Fisher ER, Gregorio RM, Fisher B, Redmond C, Vellios F, Sommers SC. The pathology of invasive breast cancer. A syllabus derived from findings of the National Surgical Adjuvant Breast Project (protocol no. 4). Cancer 1975; 36(1): 1-85

[89] Allard WJ, Matera J, Miller MC, et al. Tumor cells circulate in the peripheral blood of all major carcinomas but not in healthy subjects or patients with nonmalignant diseases. Clin Cancer Res 2004; 10(20): 6897-904.

[90] Riethdorf S, Fritsche H, Muller V, et al. Detection of circulating tumor cells in peripheral blood of patients with metastatic breast cancer: a validation study of the CellSearch system. Clin Cancer Res 2007; 13(3): 920-8.

[91] Cristofanilli M, Budd GT, Ellis MJ, et al. Circulating tumor cells, disease progression, and survival in metastatic breast cancer. $\mathrm{N}$ Engl J Med 2004; 351(8): 781-91. 
[92] Sieuwerts AM, Kraan J, Bolt J, et al. Anti-epithelial cell adhesion molecule antibodies and the detection of circulating normal-like breast tumor cells. J Natl Cancer Inst 2009; 101(1): 61-6.

[93] Ramaswamy S, Perou CM. DNA microarrays in breast cancer: the promise of personalised medicine. Lancet 2003; 361(9369): 15767.

[94] van de Vijver MJ, He YD, van't Veer LJ, et al. A gene-expression signature as a predictor of survival in breast cancer. N Engl J Med 2002; 347(25): 1999-2009.

[95] Wulfkuhle J, Espina V, Liotta L, Petricoin E. Genomic and proteomic technologies for individualisation and improvement of cancer treatment. Eur J Cancer 2004; 40(17): 2623-32.

[96] Bueno-de-Mesquita JM, van Harten WH, Retel VP, et al. Use of 70-gene signature to predict prognosis of patients with nodenegative breast cancer: a prospective community-based feasibility study (RASTER). Lancet Oncol 2007; 8(12): 1079-87.

[97] Uzan C, Andre F, Scott V, et al. Fine-needle aspiration for nucleic acid-ased molecular analyses in breast cancer. Cancer Cytopathol 2009; 117(1): 32-9.

[98] Ellis M, Davis N, Coop A, et al. Development and validation of a method for using breast core needle biopsies for gene expression microarray analyses. Clin Cancer Res 2002; 8(5): 1155-66.

[99] Pusztai L, Ayers M, Stec J, et al. Gene expression profiles obtained from fine-needle aspirations of breast cancer reliably identify routine prognostic markers and reveal large-scale molecular differences between estrogen-negative and estrogen-positive tumors. Clin Cancer Res 2003; 9(7): 2406-15.

[100] Fowler LJ, Lovell MO, Izbicka E. Fine-needle aspiration in PreservCyt: a novel and reproducible method for possible ancillary proteomic pattern expression of breast neoplasms by SELDI-TOF. Mod Pathol 2004; 17(8): 1012-20.

[101] Rapkiewicz A, Espina V, Zujewski JA, et al. The needle in the haystack: application of breast fine-needle aspirate samples to quantitative protein microarray technology. Cancer 2007; 111(3): 173-84.

[102] Rockhill B, Spiegelman D, Byrne C, Hunter DJ, Colditz GA. Validation of the Gail et al. model of breast cancer risk prediction and implications for chemoprevention. J Natl Cancer Inst 2001; 93(5): 358-66.

[103] Petroff BK, Phillips TA, Kimler BF, Fabian CJ. Detection of biomarker gene expression by real-time polymerase chain reaction using amplified ribonucleic acids from formalin-fixed random periareolar fine needle aspirates of human breast tissue. Anal Quant Cytol Histol 2006; 28(5): 297-302.

[104] Zhu W, Qin W, Hewett JE, Sauter ER. Quantitative evaluation of DNA hypermethylation in malignant and benign breast tissue and fluids. Int J Cancer 2010; 126(2): 474-82.

[105] Adduci KM, Annis CE, DeVries S, et al. Fluorescence in situ hybridization of ductal lavage samples identifies malignant phenotypes from cytologically normal cells in women with breast cancer. Cancer 2007; 111(3): 185-91. 